\title{
Effects of domestic processing methods on the phytochemical content of watercress (Nasturtium officinale)
}

Article

Accepted Version

Creative Commons: Attribution-Noncommercial-No Derivative Works 4.0

Giallourou, N., Oruna-Concha, M. J. and Harbourne, N. (2016) Effects of domestic processing methods on the phytochemical content of watercress (Nasturtium officinale). Food Chemistry, 212. pp. 411-419. ISSN 0308-8146 doi:

https://doi.org/10.1016/j.foodchem.2016.05.190 Available at https://centaur.reading.ac.uk/65845/

It is advisable to refer to the publisher's version if you intend to cite from the work. See Guidance on citing.

To link to this article DOI: http://dx.doi.org/10.1016/j.foodchem.2016.05.190

Publisher: Elsevier

All outputs in CentAUR are protected by Intellectual Property Rights law, including copyright law. Copyright and IPR is retained by the creators or other copyright holders. Terms and conditions for use of this material are defined in the End User Agreement.

www.reading.ac.uk/centaur 
Central Archive at the University of Reading

Reading's research outputs online 


\section{Title}

2 Effects of domestic processing methods on the phytochemical content of

3 watercress (Nasturtium officinale).

4 Authors Natasa Giallourou ${ }^{1}$, Maria Jose Oruna-Concha ${ }^{1}$, Niamh Harbourne ${ }^{2}$

\section{$5 \quad$ Affiliations}

$6{ }^{1}$ Department of Food and Nutritional Sciences, School of Chemistry, Food and

7 Pharmacy, University of Reading, Whiteknights campus, Reading, United

8 Kingdom,

$9{ }^{2}$ Institute of Food and Health, School of Agriculture and Food Science, University

10 College Dublin, Belfield, Dublin 4, Ireland

11

12 Corresponding author

13 Natasa Giallourou

14 Department of Food and Nutritional Sciences, School of Chemistry, Food and

15 Pharmacy, University of Reading, Whiteknights, Reading RG6 6AP, United

16 Kingdom.

17 E-mail: n.giallourou@pgr.reading.ac.uk

18 Telephone: $+44(0) 7761402005$

19 


\section{Abstract}

22 The impact of conventional cooking and processing methods on total phenols,

23 antioxidant activity, carotenoids and glucosinolates of watercress was evaluated.

24 Boiling significantly decreases phenolic content, antioxidant activity and

25 recoverable glucosinolates, however it increases the carotenoid concentrations of

26 watercress as compared to the raw vegetable. Cooking by microwaving and

27 steaming maintains the majority of phytochemicals in comparison to the fresh

28 material, suggesting that they should be used as the preferred methods of

29 watercress preparation. Boiling of watercress should be avoided to ensure

30 maximum ingestion of watercress-derived beneficial phytochemicals.

\section{Keywords}

32 Watercress; Brassica; Processing; Phytochemicals; Phenolics; Carotenoids;

33 Glucosinolates; Flavonols

\section{$34 \quad 1.0$ Introduction}

35 Watercress (Nasturtium officinale) belongs to the family of Brassicaceae

36 together with broccoli, cabbage, mustard and Brussels sprouts. Epidemiological

37 studies associate a higher intake of Brassica vegetables, such as watercress, with

38 a reduced risk of various types of cancers (Verhoeven, Goldbohm, vanPoppel,

39 Verhagen \& vandenBrandt, 1996). Watercress is an exceptional source of natural,

40 bioactive compounds for which research has highlighted a favourable role in anti-

41 genotoxic and anti-cancer processes both in vivo and in vitro (Boyd, McCann,

42 Hashim, Bennett, Gill \& Rowland, 2006; Gill, Haldar, Boyd, Bennett, Whiteford,

43 Butler, et al., 2007; Rose, Faulkner, Williamson \& Mithen, 2000). The health 
44 benefits of watercress have been attributed to phytochemicals including

45 glucosinolates, carotenoids and flavonoid compounds.

Watercress, and essentially all members of the Brassicaceae family, have

47 been identified as a rich source of glucosinolates (Bell \& Wagstaff, 2014).

48 Glucosinolates are hydrolysed to isothiocyanates by the action of the enzyme

49 myrosinase ( $\beta$-thiglucoside glucohydrolase; EC 3.2.3.1), upon cell tissue damage

50 such as mastication, chopping or cooking. This group of plant bioactive

51 compounds is responsible for the characteristic pungent taste that Brassica

52 vegetables possess. Gluconasturtiin (2-phelylethyl glucosinolate) is the most

53 prominent glucosinolate in watercress (Boyd, et al., 2006; Gill, et al., 2007) with a

54 range of aliphatic and indole glucosinolates adding to its glucosinolate profile.

High concentrations of carotenoids and flavonol compounds are also

56 contained in watercress. Carotenoids with well established health benefits such as

$57 \quad \beta$-carotene, lutein and zeaxanthin are abundant in watercresss (Hart \& Scott, 58 1995). Flavonols like quercetin, kaempferol and isorhamnetin, make up the

59 polyphenolic core of watercress (Martinez-Sanchez, Gil-Izquierdo, Gil \& Ferreres,

60 2008). Polyphenols have attracted great importance due to their many health

61 benefits related to cardiovascular function, antioxidant and anticancer activity

62 (Morel, Lescoat, Cillard, \& Cillard, 1994 Doostdar, Burke, \& Mayer, 2000; Galati,

63 Teng, Moridani, Chan, \& O'Brien, 2000).

64 While watercress is widely consumed raw in salads, it is becoming 65 increasingly popular in cooked foods such as soups, smoothies and also wilted in 66 pasta and meat dishes. Annual retail sales of watercress in the United Kingdom

67 amounted to 40 million pounds in 2015. Sales of food products with cooked or 68 processed watercress as the main ingredient have taken off the last few years, 
69 representing approximately $50 \%$ of total watercress sales (S. Rothwell, Vitacress

70 salads LTD, personal communication, March 10, 2016). Culinary processing is the

71 source of several complex biochemical and physical alterations, modifying the

72 phytochemical constituents of vegetables, ultimately resulting in nutritional

73 changes (Palermo, Pellegrini \& Fogliano, 2014).

74 To our knowledge, phytochemical characterisation of watercress subjected

75 to different culinary treatments has not been explored to date. The present

76 research was undertaken to elucidate the effects of five common cooking methods

77 on the phytochemical profile of watercress and formulate suggestions for the most

78 appropriate method for consuming watercress for maximum nutrient ingestion.

\section{$79 \quad 2.0$ Materials and methods}

$80 \quad 2.1$ Plant Material

81 Fresh watercress samples were provided from VITACRESS LTD (Andover,

82 Hampshire, UK), transferred to the laboratory and stored at $4{ }^{\circ} \mathrm{C}$ for up to 24

83 hours until all watercress processing analyses were performed. Only samples free

84 from mechanical damage were used in the experiments. All analyses were

85 performed in triplicate using the same batch of plant material to minimise variation

86 in our results.

\section{$87 \quad 2.2$ Reagents \& Chemicals}

88 All chemicals were obtained from Sigma Aldrich (Poole, UK), unless otherwise 89 stated. 


\section{$90 \quad 2.3$ Domestic Processing}

91 The effect of domestic processing on the phytochemical content and antioxidant

92 activity of watercress was examined by cooking of the plant material by boiling,

93 microwaving, steaming, chopping and blending with water to make a watercress

94 smoothie. Processing treatments and cooking times used were decided upon

95 general consumer preferences and after online search of watercress recipes as

96 well as using past research papers looking at the effects of domestic processing in

97 other types of Brassica vegetables. $100 \mathrm{~g}$ portions of watercress were used for

98 each replicate $(n=3)$. Temperature data for boiling and steaming treatments were

99 recorded throughout cooking, using a temperature logger (Squirrel OQ610-S,

100 Grant instruments, UK) and a type T thermocouple.

101 2.3.1 Boiling ( $n=3): 500 \mathrm{ml}$ of tap water was brought to boil $\left(90^{\circ} \mathrm{C}\right)$ in a stainless

102 steel pot and watercress was boiled for 2, 5 and $10 \mathrm{~min}$. Watercress was removed

103 from the boiling water and water used for cooking was kept at $-20^{\circ} \mathrm{C}$ for analysis.

104 2.3.2 Microwaving ( $n=3)$ : Fresh watercress was placed in plastic trays, then

105 transferred to a domestic microwave oven (Panasonic, UK) and cooked at full

106 power $(1400 \mathrm{~W})$ for 1,2 and $3 \mathrm{~min}$.

107 2.3.3 Steaming ( $n=3$ ): A domestic steamer (Russel Hobbs, UK) was pre-heated at

$108100{ }^{\circ} \mathrm{C}$ with $500 \mathrm{ml}$ water at its base. Watercress was placed in the steamer and

109 cooked for 5, 10 and 15 min.

110 2.3.4 Chopping ( $n=3): 100 \mathrm{~g}$ of watercress was transferred to a food processor

111 (Waring Commercial, New York, USA) and chopped for 30 secs at full speed. To

112 study the effect of storage time on the phytochemical content, the chopped

113 watercress was left on the bench at room temperature $\left(21^{\circ} \mathrm{C}\right)$ for $0,10,30,60$ 
114 and 120 min to replicate how watercress can be treated at home when chopped in

115 salads or other dishes and not consumed immediately after preparation.

116 2.3.5 Watercress smoothie $(n=3): 100 \mathrm{~g}$ of the plant material was transferred to a

117 juice maker (Vitamix, Total Nutrition Centre, UK), $200 \mathrm{ml}$ of water was added and

118 the watercress was blended for 30 secs at full power. The effect of storage time

119 was also examined by leaving the smoothie on the bench at room temperature (21

$\left.120{ }^{\circ} \mathrm{C}\right)$ for $0,10,30,60$ and $120 \mathrm{~min}$.

121 After processing, all samples were immediately frozen in liquid nitrogen then

122 freeze-dried (Christ A 2-4 LD, Christ, Germany); ground to fine powder using a

123 coffee bean grinder (De'Longhi, Italy), vacuum packed and stored at $-20^{\circ} \mathrm{C}$.

\subsection{Preparation of watercress extracts}

125 2.4.1 Crude methanol $(\mathrm{MeOH})$ extracts: The method used for the preparation of 126 the extracts was adapted from Bell et al. (Bell, Oruna-Concha \& Wagstaff, 2015)

127 Briefly, $40 \mathrm{mg}$ of ground watercress powder was heated in a dry-block at $75^{\circ} \mathrm{C}$ for $1282 \mathrm{~min}$ to inactivate myrosinase enzyme. Preheated $\left(70{ }^{\circ} \mathrm{C}\right) 70 \%(\mathrm{v} / \mathrm{v}) \mathrm{MeOH}(1 \mathrm{ml})$ 129 was then added to each sample and placed in a water bath for 20 min at $70{ }^{\circ} \mathrm{C}$.

130 Samples were then centrifuged for $5 \mathrm{~min}$ at 6,000 rpm and the supernatant was 131 transferred to fresh tubes. The final volume was adjusted to $1 \mathrm{ml}$ with $70 \%(\mathrm{v} / \mathrm{v})$

$132 \mathrm{MeOH}$ and stored at $-20^{\circ} \mathrm{C}$ until the day of analysis. $\mathrm{MeOH}$ extracts were used for 133 the FRAP assay, total phenols as well as flavonols and glucosinolates

134 identification and quantification.

135 2.4.2 Acetone extracts: Total and specific carotenoids were determined in acetone 136 watercress extracts. Watercress powder $(25 \mathrm{mg})$ was weighed out in Falcon tubes

$137(12 \mathrm{ml})$ previously wrapped in aluminium foil to minimise the degradation of 138 carotenoids by ultra-violet light. Acetone $(4 \mathrm{ml})$ was added to the powder and the 
139 samples were shaken for $15 \mathrm{~min}$ at $8000 \mathrm{rpm}$. Following centrifugation at 4000

$140 \mathrm{rpm}$ for $5 \mathrm{~min}$, the supernatant was transferred to a clean tube and the process

141 was repeated ( $4 \mathrm{ml}$ acetone for the second time and $2 \mathrm{ml}$ the third time) until a

142 colourless supernatant was obtained. The combined supernatants were

143 transferred in fresh tubes and the final volume was adjusted to $10 \mathrm{ml}$ with $100 \%$

144 acetone.

\subsection{Determination of total phenolics}

146 Total phenols were measured using the method developed by Singleton and

147 Rossi (Singleton \& Rossi, 1965) with slight modifications. Briefly, $0.2 \mathrm{ml}$ of the

$148 \mathrm{MeOH}$ watercress extract (Section 2.4) or blank was added to $6.0 \mathrm{ml}$ of distilled

149 water in volumetric flasks and mixed with $0.5 \mathrm{ml}$ of Folin - Ciocalteu reagent. A

150 sodium carbonate solution $20 \%(\mathrm{v} / \mathrm{v})(1.5 \mathrm{ml})$ was added to the mixture and the

151 volume was adjusted to $10 \mathrm{ml}$. Absorbance was read after incubation of the

152 samples for two hours at room temperature, at $760 \mathrm{~nm}$ using a UV-Vis

153 Spectrophotometer (UV-VIS, Perkin Elmers, UK). A standard curve was made

154 using gallic acid in the following concentrations: $0,50,100,150,250,500,750$

$155 \& 1000 \mathrm{mg} / \mathrm{L}$ and total phenols were measured as gallic acid equivalents $\left(\mathrm{R}^{2}>\right.$ 156 0.99).

\section{2.6 FRAP (Ferric Reducing Antioxidant Power) assay}

158 Antioxidant activity of the samples was determined using the FRAP assay based

159 on an adapted version of the method developed by Benzie and Strain (Benzie \&

160 Strain, 1996). The FRAP reagent was made by mixing $25 \mathrm{ml}$ of $300 \mathrm{mM}$ acetate

161 buffer (pH 3.6), $2.5 \mathrm{ml} 10 \mathrm{mM}$ 2,4,6-tripyridyl-s-triazine solution (TPTZ) and $2.5 \mathrm{ml}$

162 of freshly prepared ferric chloride hexahydrate $\left(\mathrm{FeCl}_{3} \cdot 6 \mathrm{H} 2 \mathrm{O}\right)$. A standard curve 
163 was made using L-Ascorbic acid in the following concentrations: $0,10,50,100$, $164250,500,750,1000 \mu \mathrm{mol} / \mathrm{L}\left(\mathrm{R}^{2}>0.99\right)$. Each $\mathrm{MeOH}$ extract (Section 2.4) or

165 standard $(10 \mu \mathrm{l})$ was combined with $300 \mu \mathrm{l}$ of the FRAP reagent and $100 \mu \mathrm{l}$ of the

166 mixture was transferred in duplicate in a 96-well plate. Absorbance was measured

167 immediately using a plate reader (Tecan GENios, Geneva, Switzerland) at 595 $168 \mathrm{~nm}$.

1692.7 Total carotenoids

170 An aliquot of the acetone extracts prepared as previously described (Section 2.4) 171 was used to quantify the total carotenoid content of the samples

172 spectrophotometrically. Absorbance was measured at 470, 645 and $662 \mathrm{~nm}$ in a 173 spectrophotometer (UV-VIS, Perkin Elmers, UK). The total amount of carotenoids 174 was calculated according to the following equations by Lichtenthaler (Lichtenthaler 175 \& Buschmann, 2001).

$$
\begin{gathered}
C_{a}=11.24 A_{662}-2.04 A_{645} \\
C_{b}=20.13 A_{645}-4.19 A_{662} \\
C_{a+b}=7.05 A_{662}+18.09 A_{645} \\
C_{x+c}=\frac{1000 A_{470}-190 C_{a}-63.14 C_{b}}{214}
\end{gathered}
$$

$181{ }^{*}$ Chlorophyll a $\left(C_{a}\right)$, Chlorophyll b $\left(C_{b}\right)$, Total Chlorophylls $\left(C_{a+b}\right)$, Total Carotenoids $182\left(C_{x+c}\right)$. Equations are based on specific absorption coefficients for $100 \%$ acetone. The pigment 183 concentrations obtained by inserting the measures absorbance values are $\mu \mathrm{g} / \mathrm{ml}$ plant extract 184 solution. 
186 To determine the amount of lutein, zeaxanthin and $\beta$-carotene present, the

187 acetone extracts were used (Section 2.4). Carotenoids were quantified using the

188 method developed by Guiffrida et al. (Giuffrida, Dugo, Torre, Bignardi, Cavazza,

189 Corradini, et al., 2013) with modifications.10 $\mathrm{ml}$ of the extract was mixed with 10

$190 \mathrm{ml}$ of diethyl ether, $10 \mathrm{ml}$ of water and $5 \mathrm{ml}$ of $10 \%(\mathrm{v} / \mathrm{v}) \mathrm{NaCl}$. Two layers were

191 formed and the lower - acetone phase was discarded. The upper layer containing

192 the ether was collected in a glass vial and anhydrous $\mathrm{Na}_{2} \mathrm{SO}_{4}$ was added to it to

193 remove any moisture from the solution. The ether phase was transferred to a

194 clean glass vial, the volume was adjusted to $10 \mathrm{ml}$ with diethyl ether and the

195 solution was condensed under nitrogen gas. The dry residue was then

196 reconstituted in $1 \mathrm{ml}$ of methyl tert- butyl ether (MTBE):MeOH (1:1, v/v), filtered

197 using $0.22 \mu \mathrm{m}$ syringe driven filter unit and analysed by HPLC. The analyses

198 were performed using an YMC30 column (5 $\mathrm{mm} 250 \times 4.6 \mathrm{~mm})$ on a HP Agilent

1991050 series HPLC system. The mobile phases used were as follows: Eluent A,

200 consisting of $\mathrm{MeOH}: \mathrm{MTBE}: \mathrm{H}_{2} \mathrm{O}(82: 16: 2 \mathrm{v} / \mathrm{v} / \mathrm{v})$ and Eluent $\mathrm{B}$, consisting of

$201 \mathrm{MeOH}: \mathrm{MTBE}: \mathrm{H}_{2} \mathrm{O}(23: 75: 2 \mathrm{v} / \mathrm{v} / \mathrm{v})$. The analyses followed a gradient program for

202 the mobile phases, $0 \min 0 \% \mathrm{~B}, 20 \min 0 \% \mathrm{~B}, 80 \min 70 \% \mathrm{~B}, 90 \min 70 \% \mathrm{~B}$. The

203 protocol used a $1 \mathrm{~mL} / \mathrm{min}$ flow rate and a $100 \mu \mathrm{L}$ injection volume. UV-vis spectra

204 were gathered in the range of $190-600 \mathrm{~nm}$ and the chromatograms were analysed

205 at $450 \mathrm{~nm}$. Identification was based on retention times by comparison with HPLC

206 grade standards of lutein, zeaxanthin and $\beta$-carotene (Extrasynthese, France).

2072.9 Identification and quantification of glucosinolates and flavonols via LC-

208 MS/MS

209 Methanol extracts, prepared as described above, were used for the quantification 
210 of glucosinolates and flavonols in the samples (Section 2.4.1). $1 \mathrm{ml}$ of each extract

211 was filtered using a $0.22 \mu \mathrm{m}$ syringe driven filter unit (Millex; EMD Millipore,

212 Billerica, MA, USA) and then diluted using 9ml LC-MS grade water. For the

213 quantification of glucosinolates and flavonols, external calibration curves of $12 \mathrm{mM}$

214 sinigrin hydrate and isorhamnetin standards were prepared using the following

215 concentrations (56 ng. $\mu^{-1}, 42 \mathrm{ng} \cdot \mathrm{\mu l}^{-1}, 28 \mathrm{ng} \cdot \mathrm{\mu l}^{-1}, 14 \mathrm{ng} \cdot \mathrm{Il}^{-1}, 5.6 \mathrm{ng} \cdot \mathrm{ll}^{-1}, \mathrm{R}^{2}>0.99$ ).

216 Glucosinolates and flavonols were analysed by LC-MS/MS using an Agilent 1200

217 LC system coupled to an Agilent 1100 series LC/MSD mass trap spectrometer.

218 Separation conditions of samples and MS analysis settings used are identical to

219 those described by Bell, et al. (2015) . Glucosinolates were quantified at $229 \mathrm{~nm}$

220 and flavonols at $330 \mathrm{~nm}$. The identification was performed using the compounds

221 nominal mass and the analysis of their fragmentation patterns, and also by the

222 comparison with previously published data. All data were analysed using Agilent

223 ChemStation.

224 2.10 Statistical Analysis

225 The results are presented as the mean of three biological replicates $(n=3)$ for

226 each sample. One-way ANOVA and Dunnett's multiple comparisons test were

227 used for comparison of all treatments related to the raw watercress. These

228 analyses were carried out using GraphPad Prism version 5.0a for Mac OS

229 X,GraphPad software (Version 5.0a La Jolla, California, USA). Principal

230 component analysis (PCA) and correlation analysis were performed using XL Stat

231 (Version 2016 Addinsoft, New York City, New York, USA). 


\subsection{Results and Discussion}

\section{3.1 Total phenols content}

234 Fresh watercress had the highest amount of total phenols (14.86 $\pm 2.02 \mathrm{mg} \mathrm{GAE}$ $235 \mathrm{~g}^{-1} \mathrm{DW}$ ) compared to the processed samples (Figure 1A). Our results are in 236 agreement with that of Aires, Carvalho, Rosa and Saavedra (2013) who found the

237 phenolic content of watercress to be $14.00 \pm 0.03 \mathrm{mg} \mathrm{GAE} \mathrm{g}^{-1} \mathrm{DW}$. In comparison

238 to other vegetables in the Brassica family, watercress is a rich source of phenolic 239 compounds. It has a similar amount to kale $\left(16.67 \pm 0.67 \mathrm{mg} \mathrm{GAE} \mathrm{g}^{-1} \mathrm{DW}\right)$ 240 (Hagen, Borge, Solhaug \& Bengtsson, 2009) and it is much higher than broccoli

241 and cabbage which have a lower phenolic content that being $8.86 \mathrm{mg}$ and $5.6 \mathrm{mg}$

242 GAE g-1 DW respectively (Gliszczynska-Swiglo, Ciska, Pawlak-Lemanska,

243 Chmielewski, Borkowski \& Tyrakowska, 2006; Puupponen-Pimiä, Häkkinen,

244 Aarni, Suortti, Lampi, Eurola, et al., 2003).

245 Boiling of watercress resulted in a significant decrease $(P<0.05)$ in the total 246 phenolic content in comparison with the fresh samples. Total phenolic losses 247 ranged from $49 \%$ to $71 \%$ in the samples boiled for 2 and 10 minutes respectively.

248 Microwaving and steaming for up to 5 minutes did not significantly affect the 249 phenolic content of watercress $(P>0.05)$. Likewise, blending with water to make a 250 watercress smoothie and chopping did not have a significant effect on the total 251 phenolic content in the watercress. However, storage of the smoothies and the 252 chopped watercress samples for 120 minutes at room temperature resulted in a 253 significant reduction of the phenolics from $13.65 \pm 1.56$ to $10.76 \pm 1.15 \mathrm{mg} \mathrm{GAE} \mathrm{g}$

$254{ }^{1} \mathrm{DW}$ and from $10.55 \pm 1.48$ to $8.65 \pm 2.29 \mathrm{mg} \mathrm{GAE} \mathrm{g}^{-1} \mathrm{DW}$ respectively (Figure $2551 \mathrm{~A})$. 
256 Our results are corroborated by previous studies showing that boiling of Brassica

257 vegetables can lead to significant time dependant losses of phenolics whereas

258 microwaving and steaming led to only minor decreases in the phenolic content of

259 broccoli (Turkmen, Sari \& Velioglu, 2005; Zhang \& Hamauzu, 2004), red cabbage

260 (Podsedek, Sosnowska, Redzynia \& Koziolkiewicz, 2008) and cauliflower (Natella,

261 Belelli, Ramberti \& Scaccini, 2010). During the process of cooking, phenolic

262 compounds appear to be highly reactive undergoing several changes including

263 their release from bound forms, oxidation, degradation and polymerisation

264 (Gliszczynska-Swiglo, et al., 2006).

265 The losses during boiling can be attributed to water-soluble compounds leaching

266 into the water used for boiling or due to breakdown of these compounds during

267 thermal processing. Indeed, analysis of the water used in the boiling experiments

268 (9.35 $\left.\pm 0.12 \mathrm{mg} \mathrm{GAE} \mathrm{g}^{-1} \mathrm{DW}\right)$ for total phenolics revealed that phenols had

269 leached into the boiling water. The total amount of phenols in the water used in

270 boiling and the remaining phenol content of watercress was no different from the

271 total phenols in raw watercress. The minimal effect of microwaving and steaming

272 on the phenolic compounds is potentially a result of limited or no contact of the

273 samples with water and also the inactivation of oxidative enzymes preventing the

274 disruption of phenolic biosynthesis and degradation (Vallejo, Tomás-Barberán \&

275 García-Viguera, 2003).

276 3.2 Flavonols identification and quantification

277 Flavonol profiling of watercress revealed three main derivatives namely 278 kaempferol, quercetin and isorhamnetin as well as feruloyl, ceffeoyl, p-coumaroyl

279 and sinapoyl glucosides attached to kaempferol and quercetin. Kampferol-3-

280 diglucoside-7-glucoside was the most abundant flavonol detected $(3.76 \pm 0.09 \mathrm{mg}$ 
$\left.281 \mathrm{~g}^{-1} \mathrm{DW}\right)$. The flavonols identified in the fresh watercress leaves are similar to those

282 defined by Martinez-Sanchez, et al. (2008).

283 Domestic processing of watercress resulted in a significant decrease in the levels

284 of all quantified flavonols (Table 1). The only exception was Q 3,4'diGlc-3'-

285 (p.coum-Glc) + K 3,4'-diGlc which appeared to be the most stable of all flavonols

286 and were only significantly affected by boiling $(\mathrm{P}<0.05)$. Total flavonol losses

287 suggest that these compounds are particularly sensitive to all cooking regimes

288 used. Boiling for 10 minutes nearly depleted all watercress samples of flavonols in

289 a time dependent manner. The unstable nature of flavonols was also apparent in

290 chopped watercress and watercress smoothie with the levels going down to $3.42 \pm$

2910.32 and $4.11 \pm 0.36 \mathrm{mg} \mathrm{g}^{-1} \mathrm{DW}$ respectively as compared to the total amount of

292 flavonols in the fresh samples $\left(10.70 \pm 1.07 \mathrm{mg} \mathrm{g}^{-1} \mathrm{DW}, \mathrm{P}<0.001\right)$. Similarly to total

293 phenols, the highest retention of flavonols was observed in the microwaved

294 watercress followed by steamed.

\section{3.3 Carotenoid content}

296 In contrast to the previous assays, boiling of watercress resulted in an increased

297 concentration of total measurable carotenoids, from $2.35 \pm 0.22 \mathrm{mg} \mathrm{g}^{-1} \mathrm{DW}$ in the

298 fresh samples to $3.13 \pm 0.20 \mathrm{mg} \mathrm{g}^{-1} \mathrm{DW}$ after 2 minutes of cooking and up to 3.28

$299 \pm 0.30 \mathrm{mg} \mathrm{g}^{-1} \mathrm{DW}$ after 5 minutes of boiling (Table 1). Microwaving and steaming

300 did not have a significant impact on the level of total carotenoids $(P>0.05)$. On the

301 other hand, the watercress smoothie had significantly lower total carotenoid

302 content, with the levels decreasing from $1.54 \pm 0.21$ to $1.11 \pm 0.08 \mathrm{mg} \mathrm{g}^{-1} \mathrm{DW}$ after

30360 minutes of storage at ambient temperature. A similar decreasing trend was

304 observed in the chopped watercress samples. 
305 The individual carotenoids identified and quantified in our watercress samples 306 were $\beta$-carotene, lutein and zeaxanthin and they all resulted in distinct responses 307 upon domestic processing. $\quad \beta$-carotene was the most abundant of the three 308 quantified carotenoids $\left(0.95 \pm 0.08 \mathrm{mg} \mathrm{g}^{-1} \mathrm{DW}\right)$ and its levels significantly

309 increased after thermal treatment of the watercress samples. Boiling for 5 minutes

310 resulted in $\beta$-carotene being significantly increased up to $1.75 \pm 0.09 \mathrm{mg} \mathrm{g}^{-1} \mathrm{DW}$ 311 as compared to the raw samples $(P<0.001)$. In the microwaved watercress

312 samples $\beta$-carotene was increased up to $1.48 \pm 0.26 \mathrm{mg} \mathrm{g}^{-1} \mathrm{DW}(\mathrm{P}<0.01)$ and in

313 the samples steamed for 15 minutes levels went up to $1.54 \pm 0.07 \mathrm{mg} \mathrm{g}^{-1} \mathrm{DW}$

$314(\mathrm{P}<0.001) . \quad \beta$-carotene was decreased in the watercress smoothie only after 315 storage for 30 and 60 and 120 minutes $(P<0.01)$ therefore, immediate 316 consumption of a watercress smoothie ensures sufficient intake of $\beta$-carotene. No 317 significant differences were found in the chopped samples.

318 Lutein content of fresh watercress samples was $0.24 \pm 0.02 \mathrm{mg} \mathrm{g}^{-1} \mathrm{DW}$ and it 319 exhibited the highest degree of stability after watercress processing. It was 320 significantly increased only after 5 minutes of boiling going up to $0.36 \pm 0.02 \mathrm{mg} \mathrm{g}^{-}$ $321{ }^{1} \mathrm{DW} \quad(\mathrm{P}<0.05)$. Significant decreases in lutein were only observed in the smoothie 322 after 120 minutes of storage $(\mathrm{P}<0.05)$. Zeaxanthin concentration in fresh

323 watercress was notably lower than $\beta$-carotene and lutein $\left(0.02 \pm 0.00 \mathrm{mg} \mathrm{g}^{-1} \mathrm{DW}\right)$.

324 It was dramatically affected by boiling with increases higher than 6 and 3 times, as 325 compared to fresh watercress, after boiling for 5 minutes and steaming for 10 326 minutes respectively.

327 Increases in the carotenoid contents of other Brassica vegetables such as 328 broccoli, Brussels sprouts, cabbage and cauliflower upon boiling and steaming 329 have been reported by a number of research groups (Bernhardt \& Schlich, 2006; 
330 Gliszczynska-Swiglo, et al., 2006; Hart, et al., 1995). Elevations in the measurable

331 carotenoid concentrations after thermal treatments can be explained by changes

332 in the plant cell wall due to the breakdown of cellulose as well as improved

333 extractability of carotenoids from the plant as a result of the denaturation of

334 carotenoid-protein complexes due to thermal processing (Khachik, Beecher, Goli

335 \& Lusby, 1991).

\section{3.4 Glucosinolate identification and quantification}

337 Gluconasturtiin was the most abundant glucosinolate in fresh and cooked

338 watercress samples followed by the indole glucosinolates: glucobrassicin, 4-

339 methoxyglucobrassicin, 4-hydroxyglucobrassicin and the aliphatic glucosinolate

340 glucoibarin (Table 3). The profile characterised here is similar to that previously

341 defined by Boyd, et al. (2006); Gill, et al. (2007).

342 Glucosinolate quantification revealed a major impact of cooking on the levels of

343 these phytochemicals. Boiling reduced the levels of total glucosinolates by up to

$34463 \%$ and led to significant loses of all the individual glucosinolates identified in this

345 study $(\mathrm{P}<0.001)$. Considerable glucosinolate losses after boiling of Brassica

346 vegetables like broccoli, cauliflower and Brussels sprouts, have also been

347 observed in other studies performed by a number of research groups (Song \&

348 Thornalley, 2007; Vallejo, Tomás-Barberán \& Garcia-Viguera, 2002). Heat

349 application combined with cooking in water can result in depletion of

350 glucosinolates in Brassica as a result of enzyme activity modification and

351 thermally induced breakdown processes (Jones, 2007; Palermo, et al., 2014).

352 Boiling of watercress in water caused significant loss of glucosinolates that most

353 likely have leached into the cooking water. Similar conclusions were drawn by

354 Song, et al. (2007) who showed that boiling of Brassica vegetables leads to 
355 significant leaching of glucosinolates in the boiling water. Jones (2007) have

356 shown that the glucosinolate losses in Brassica vegetables are positively

357 correlated with the cooking time.

358 Microwaving and steaming had a subtle effect on glucosinolate concentrations

359 with minor losses at the longest cooking duration, as compared to the other

360 treatments. Microwaving and steaming for 2 or 5 minutes did not result in major

361 losses of total glucosinolates suggesting that these cooking methods will ensure a

362 higher retention rate of these phytochemicals. Our results are in agreement with

363 that of Song, et al. (2007) who examined the impact of different cooking methods

364 on broccoli, brussels sprouts, cauliflower and green cabbage. This observation is

365 likely due to denaturation and subsequent deactivation of the myrosinase enzyme,

366 which depletes glucosinolates in favour of their hydrolysis to isothiocyanates, after

367 application of high temperatures during cooking (Verkerk, vanderGaag, Dekker \&

368 Jongen, 1997). We found that cooking by steaming resulted in a slight increase in

369 gluconasturtiin concentrations from 1.76 to $2.04 \mathrm{mg} \mathrm{g}^{-1} \mathrm{DW}(\mathrm{P}<0.05)$ and it can

370 therefore be considered as the preferred method of watercress consumption to

371 maximise gluconasturtiin levels. Elevated gluconasturtiin concentrations upon

372 steaming are also reported by Gliszczynska-Swiglo, et al. (2006) in broccoli.

373 Increases in other glucosinolates in Brassica vegetables subjected to steaming

374 have been also been noted in a number of studies (Pellegrini, Chiavaro, Gardana,

375 Mazzeo, Contino, Gallo, et al., 2010; Vallejo, et al., 2002). The inactivation of

376 myrosinase at the high temperatures such as the ones reached during steaming,

377 can temporarily cease the conversion of glucosinolates to isothiocyanates

378 (Vallejo, et al., 2002) a process which can be undertaken post ingestion, in vivo,

379 by the action of the endogenous bacterial myrosinase in the gut (Rouzaud, Rabot, 
380 Ratcliffe \& Duncan, 2003). Furthermore, heat application leads to plant cell

381 structure disintegration allowing glucosinolates to be released from their bound

382 forms on the plant cell wall making these compounds more recoverable during

383 extraction (Gliszczynska-Swiglo, et al., 2006). Steaming is performed without

384 direct contact of the plant material and water, preventing the leaching of

385 glucosinolates into it.

386 Homogenisation by blending watercress with water to create a smoothie resulted

387 in dramatic reductions in glucosinolates stemming mainly from the complete loss

388 of gluconasturtiin $(P<0.001)$. Upon chopping losses ranged from $35 \%$ to $46 \%$ after

389120 minutes of storage at room temperature. Chopping of vegetables before

390 consumption is a regular practise and this can lead to decreased glucosinolate

391 content since they are exposed to myrosinase for conversion to isothiocyanates.

392 This was reflected in our results and those of others (Smith, Mithen \& Johnson,

393 2003; Song, et al., 2007), and it was particularly apparent in the gluconasturtiin

394 quantification. When watercress was homogenised to create a smoothie,

395 gluconasturtiin was completely lost and the levels of other glucosinolates were

396 significantly diminished. Our results are comparable with results from a study

397 performed by Smith, et al. (2003) where homogenisation for juice extraction from

398 Brussels sprouts led to loss of glucosinolates which were converted to

399 isothiocyanates and other breakdown products due to the exposure of

400 glucosinolates to myrosinase enzyme. Song, et al. (2007) observed that shredding

401 of Brassica vegetables and subsequent storage at ambient temperature results in

402 major losses of glucosinolates with concurrent formation of isothiocyanates.

403 Isothiocyanates such as PEITC are highly volatile compounds therefore they are

404 prone to evaporation as observed by Rose, et al. (2000) who did not detect PEITC 
405 in watercress aqueous extracts. However, Ji, Kuo and Morris (2005) noted that

406 PEITC remains stable in aqueous buffers with a half-life of $56 \mathrm{~h}$ at ambient

407 temperature. This suggests that smoothies or juices made from watercress, which

408 is rich in PEITC, should be freshly consumed after preparation to ensure adequate

409 ingestion.

\section{$410 \quad 3.5$ Antioxidant activity}

411 The antioxidant activity of all watercress samples was determined using the FRAP

412 assay (Figure 1B). Fresh watercress had an antioxidant activity of $74.54 \pm 10.81$

$413 \mu \mathrm{mol}$ AAE $\mathrm{g}^{-1} \mathrm{DW}$. Watercress was found to have the highest antioxidant activity

414 when compared to spinach, rocket and mizuna (Martinez-Sanchez, et al., 2008;

415 Payne, Mazzer, Clarkson \& Taylor, 2013).

416 Boiling dramatically decreased the antioxidant capacity of watercress over time as

417 compared to raw watercress, with losses reaching $67 \%$ of total antioxidant activity

418 for samples cooked for 10 minutes (Figure 1B). Antioxidant activity analysis of the

419 cooking water showed that the losses observed during boiling are due to leaching

420 of antioxidant compounds in the water $\left(46,03 \pm 9.42 \mu \mathrm{mol}\right.$ AAE $\left.\mathrm{g}^{-1} \mathrm{DW}\right)$. In

421 contrast, microwaving and steaming of watercress did not result in any significant

422 losses. Chopping and blending to smoothie had no significant impact on the

423 antioxidant activity of the samples, however storage of these samples at room

424 temperature for 30 or 120 minutes resulted in a significant decrease in antioxidant

425 activity. Chopping and blending to smoothie reduced the antioxidant activity to

$42642.84 \pm 8.00$ and $48.47 \pm 9.63 \mu \mathrm{mol} A A E g^{-1} \mathrm{DW}$ at 120 minutes of storage

427 respectively. The antioxidant activity of raw and cooked samples followed a similar

428 trend to that found for total phenols with a significant correlation between these

429 measures $\left(R^{2}=0.759, P<0.05\right)$. 
430 In a study carried out by Ismail, Marjan and Foong (2004) it was found that boiling

431 for 1 minute significantly decreased the antioxidant activity of kale, but not that of

432 cabbage. Zhang and Hamauzu Zhang, et al. (2004) showed that after boiling and

433 microwaving, broccoli lost $65 \%$ and $65.3 \%$ of its total antioxidant activity

434 respectively.

435 Since the antioxidant activity of plants may be defined by the concentration of 436 phenols and ascorbic acid in combination with other phytochemicals, leaching of

437 these compounds into the boiling water, or oxidation and degradation of them

438 during cooking, can lead to lower antioxidant activity of watercress (Gliszczynska-

439 Swiglo, et al., 2006; Vallejo, et al., 2003).

$440 \quad 3.6$ Watercress phytochemical profile modifications upon cooking

441 PCA revealed distinct phytochemical profiles for watercress cooked using different

442 regimes (Figure 2). The profiles obtained from microwaved and steamed

443 watercress closely resembled that of fresh watercress with these cooking

444 methodologies positively correlating with the phenolics, carotenoids and

445 glucosinolate concentrations. In stark contrast, boiled watercress has a

446 phytochemical profile very different from that of fresh watercress characterised by

447 elevated carotenoid amounts $\left(R^{2}=0.668\right)$ and significant losses in glucosinolates

448 and flavonols, which essentially result in compromised antioxidant activity $\left(R^{2}=\right.$

449 -0.596). Chopped watercress and watercress smoothie samples have similar

450 phytochemical profiles and separate from the fresh samples on the first principal

451 component characterised by losses of all the phytochemicals quantified in our

452 study. Cooking time appears to be negatively correlated with microwaving, boiling

453 and steaming but exposure of chopped samples and watercress smoothie to

454 ambient temperature for extended time periods does not appear to have a 
455 particular impact on the measureable phytochemicals in these samples, expect in

456 the total phenolic content of stored chopped watercress. Antioxidant activity as

457 measured by the FRAP assay, exhibits a significant positive correlation with

458 microwaving $\left(\mathrm{R}^{2}=0.452\right)$ driven by higher concentrations of glucosinolates and

459 flavonols suggesting that it should be the preferred method of watercress

460 preparation when it is not consumed raw.

\section{$461 \quad 4.0$ Conclusions}

462 This study clearly demonstrates that health-promoting compounds in watercress

463 are significantly influenced by domestic processing methods. Cooking by

464 microwaving and steaming preserves the levels of most phytochemicals in

465 watercress. Domestic processing can have a detrimental effect on the bioactives

466 which may be responsible for the health promoting properties of watercress.

467 Satisfactory retention of beneficial phytochemicals in watercress may be achieved

468 by avoiding boiling which results in a compromised phytochemical profile.

\section{Acknowledgements}

470 This study was supported by the Agricultural and Horticulture Development

471 Board (Kenilworth, UK). The authors would like to thank VITACRESS Salads Ltd

472 (Andover, Hampshire, UK) for the kind provision of fresh watercress samples used

473 in the experiments.

\section{References}

475 Aires, A., Carvalho, R., Rosa, E. A. S., \& Saavedra, M. J. (2013). Phytochemical characterization and antioxidant properties of baby-leaf watercress produced under organic production system. CyTA - Journal of Food, 11(4), 343-351.

Bell, Oruna-Concha, M. J., \& Wagstaff, C. (2015). Identification and quantification of glucosinolate and flavonol compounds in rocket salad (Eruca sativa, Eruca vesicaria and Diplotaxis tenuifolia) by LC-MS: Highlighting the 
potential for improving nutritional value of rocket crops. Food Chemistry, $172,852-861$.

Bell, \& Wagstaff, C. (2014). Glucosinolates, Myrosinase Hydrolysis Products, and Flavonols Found in Rocket (Eruca sativa and Diplotaxis tenuifolia). J Agric Food Chem, 62(20), 4481-4492.

Benzie, I. F. F., \& Strain, J. J. (1996). The Ferric Reducing Ability of Plasma (FRAP) as a Measure of "Antioxidant Power": The FRAP Assay. Analytical Biochemistry, 239(1), 70-76.

Bernhardt, S., \& Schlich, E. (2006). Impact of different cooking methods on food quality: Retention of lipophilic vitamins in fresh and frozen vegetables. Journal of Food Engineering, 77(2), 327-333.

Boyd, L. A., McCann, M. J., Hashim, Y., Bennett, R. N., Gill, C. I., \& Rowland, I. R. (2006). Assessment of the anti-genotoxic, anti-proliferative, and antimetastatic potential of crude watercress extract in human colon cancer cells. Nutr Cancer, 55(2), 232-241.

Gill, C. I. R., Haldar, S., Boyd, L. A., Bennett, R., Whiteford, J., Butler, M., Pearson, J. R., Bradbury, I., \& Rowland, I. R. (2007). Watercress supplementation in diet reduces lymphocyte DNA damage and alters blood antioxidant status in healthy adults. American Journal of Clinical Nutrition, 85(2), 504-510.

Giuffrida, D., Dugo, P., Torre, G., Bignardi, C., Cavazza, A., Corradini, C., \& Dugo, G. (2013). Characterization of 12 Capsicum varieties by evaluation of their carotenoid profile and pungency determination. Food Chem, 140(4), 794802.

Gliszczynska-Swiglo, A., Ciska, E., Pawlak-Lemanska, K., Chmielewski, J., Borkowski, T., \& Tyrakowska, B. (2006). Changes in the content of healthpromoting compounds and antioxidant activity of broccoli after domestic processing. Food Addit Contam, 23(11), 1088-1098.

Hagen, S. F., Borge, G. I. A., Solhaug, K. A., \& Bengtsson, G. B. (2009). Effect of cold storage and harvest date on bioactive compounds in curly kale (Brassica oleracea L. var. acephala). Postharvest Biology and Technology, 51(1), 36-42.

Hart, D. J., \& Scott, K. J. (1995). Development and Evaluation of an Hplc Method for the Analysis of Carotenoids in Foods, and the Measurement of the Carotenoid Content of Vegetables and Fruits Commonly Consumed in the Uk. Food Chemistry, 54(1), 101-111.

Ismail, A., Marjan, Z. M., \& Foong, C. W. (2004). Total antioxidant activity and phenolic content in selected vegetables. Food Chemistry, 87(4), 581-586.

Ji, Y., Kuo, Y., \& Morris, M. (2005). Pharmacokinetics of Dietary Phenethyl Isothiocyanate in Rats. Pharmaceutical Research, 22(10), 1658-1666.

Jones, R. B. (2007). Effects of postharvest handling conditions and cooking on anthocyanin, lycopene, and glucosinolate content and bioavailability in fruits and vegetables. New Zealand Journal of Crop and Horticultural Science, 35(2), 219-227.

Khachik, F., Beecher, G. R., Goli, M. B., \& Lusby, W. R. (1991). Separation, Identification, and Quantification of Carotenoids in Fruits, Vegetables and Human Plasma by High-Performance Liquid-Chromatography. Pure and Applied Chemistry, 63(1), 71-80. 
Lichtenthaler, H. K., \& Buschmann, C. (2001). Chlorophylls and Carotenoids: Measurement and Characterization by UV-VIS Spectroscopy. In Current Protocols in Food Analytical Chemistry): John Wiley \& Sons, Inc.

Martinez-Sanchez, A., Gil-Izquierdo, A., Gil, M. I., \& Ferreres, F. (2008). A comparative study of flavonoid compounds, vitamin $\mathrm{C}$, and antioxidant properties of baby leaf Brassicaceae species. J Agric Food Chem, 56(7), 2330-2340.

Natella, F., Belelli, F., Ramberti, A., \& Scaccini, C. (2010). Microwave And Traditional Cooking Methods: Effect Of Cooking On Antioxidant Capacity And Phenolic Compounds Content Of Seven Vegetables. Journal of Food Biochemistry, 34(4), 796-810.

Palermo, M., Pellegrini, N., \& Fogliano, V. (2014). The effect of cooking on the phytochemical content of vegetables. J Sci Food Agric, 94(6), 1057-1070.

Payne, A. C., Mazzer, A., Clarkson, G. J. J., \& Taylor, G. (2013). Antioxidant assays - consistent findings from FRAP and ORAC reveal a negative impact of organic cultivation on antioxidant potential in spinach but not watercress or rocket leaves. Food Sci Nutr, 1(6), 439-444.

Pellegrini, N., Chiavaro, E., Gardana, C., Mazzeo, T., Contino, D., Gallo, M., Riso, P., Fogliano, V., \& Porrini, M. (2010). Effect of Different Cooking Methods on Color, Phytochemical Concentration, and Antioxidant Capacity of Raw and Frozen Brassica Vegetables. J Agric Food Chem, 58(7), 4310-4321.

Podsedek, A., Sosnowska, D., Redzynia, M., \& Koziolkiewicz, M. (2008). Effect of domestic cooking on the red cabbage hydrophilic antioxidants. International Journal of Food Science and Technology, 43(10), 1770-1777.

Puupponen-Pimiä, R., Häkkinen, S. T., Aarni, M., Suortti, T., Lampi, A.-M., Eurola, M., Piironen, V., Nuutila, A. M., \& Oksman-Caldentey, K.-M. (2003). Blanching and long-term freezing affect various bioactive compounds of vegetables in different ways. J Sci Food Agric, 83(14), 1389-1402.

Rose, P., Faulkner, K., Williamson, G., \& Mithen, R. (2000). 7-Methylsulfinylheptyl and 8-methylsulfinyloctyl isothiocyanates from watercress are potent inducers of phase II enzymes. Carcinogenesis, 21(11), 1983-1988.

Rouzaud, G., Rabot, S., Ratcliffe, B., \& Duncan, A. J. (2003). Influence of plant and bacterial myrosinase activity on the metabolic fate of glucosinolates in gnotobiotic rats. British Journal of Nutrition, 90(2), 395-404.

Singleton, V. L., \& Rossi, J. A. (1965). Colorimetry of Total Phenolics with Phosphomolybdic-Phosphotungstic Acid Reagents. American Journal of Enology and Viticulture, 16(3), 144-158.

Smith, T. K., Mithen, R., \& Johnson, I. T. (2003). Effects of Brassica vegetable juice on the induction of apoptosis and aberrant crypt foci in rat colonic mucosal crypts in vivo. Carcinogenesis, 24(3), 491-495.

Song, L., \& Thornalley, P. J. (2007). Effect of storage, processing and cooking on glucosinolate content of Brassica vegetables. Food Chem Toxicol, 45(2), 216-224.

Turkmen, N., Sari, F., \& Velioglu, Y. S. (2005). The effect of cooking methods on total phenolics and antioxidant activity of selected green vegetables. Food Chemistry, 93(4), 713-718.

Vallejo, F., Tomás-Barberán, F. A., \& Garcia-Viguera, C. (2002). Glucosinolates and vitamin $\mathrm{C}$ content in edible parts of broccoli florets after domestic cooking. European Food Research and Technology, 215(4), 310-316. 
579

580

581

582

583

584

585

586

587

588

589

590

591

592

593

594

595

596

597

598

599

600

601

602

603

604

605

606

607

608

609

610

Vallejo, F., Tomás-Barberán, F. A., \& García-Viguera, C. (2003). Phenolic compound contents in edible parts of broccoli inflorescences after domestic cooking. J Sci Food Agric, 83(14), 1511-1516.

Verhoeven, D. T. H., Goldbohm, R. A., vanPoppel, G., Verhagen, H., \& vandenBrandt, P. A. (1996). Epidemiological studies on brassica vegetables and cancer risk. Cancer Epidemiology Biomarkers \& Prevention, 5(9), 733-748.

Verkerk, R., vanderGaag, M. S., Dekker, M., \& Jongen, W. M. F. (1997). Effects of processing conditions on glucosinolates in cruciferous vegetables. Cancer Letters, 114(1-2), 193-194.

Zhang, D. L., \& Hamauzu, Y. (2004). Phenolics, ascorbic acid, carotenoids and antioxidant activity of broccoli and their changes during conventional and microwave cooking. Food Chemistry, 88(4), 503-509.

Figure 1 (A) Total phenols content in raw and processed samples expressed as gallic acid equivalents (GAE) in $\mathrm{mg} \mathrm{g}^{-1}$ of dry weight (DW). (B) FRAP-assay results for the measurement of the antioxidant activity in raw and cooked watercress samples. Results are presented as ascorbic acid equivalents (AAE) in $\mathrm{mg} \mathrm{g}^{-1}$ of DW. Data is mean of three biological replicates + SD. Significance: ${ }^{*}, \mathrm{P}<0.05$; $^{* *}$, $\mathrm{P}<0.01 ;{ }^{* *} \mathrm{P}<0.001$ as compared to carotenoid content of raw watercress. (BD: Boiled, MW: Microwaved, ST: Steamed, SM: Smoothie, CH: Chopped.

Figure 2 PCA scores of all cooked samples ( $\square$ ) and loadings plot for all quantified phytochemicals (O). Abbreviations: 4-MGB, 4-methoxyglucobrassicin; 4-HGB, 4-hydroxyglucobrassicin; KSG, K 3-(sinp-Glc)-4'Glc; KSTG, K 3-(sinptriGlc)-7-Glc; QDGCG, QCSG, Q 3-(caf-Glc)-3'-(sinp-Glc)-4'-Glc; KDG, K 3-diGlc7-Glc; IG, I 3-Glc; KFTG, K 3-(fer-triGlc)-7 Glc; QCG+KDG Q 3,4'diGlc-3'-(p.coumGlc) + K 3,4'-diGlc.

Table 1 Concentration of individual and average total flavonols in raw and processed watercress samples. Data is presented in $\mathrm{mg} \mathrm{g}^{-1}$ of DW (mean $\pm \mathrm{SD}$ ). Experiment was performed with three biological replicates per group. Significance: ${ }^{*}, \mathrm{P}<0.05 ;{ }^{* *}, \mathrm{P}<0.01 ;{ }^{* \star} \mathrm{P}<0.001$ as compared to flavonoid content of raw watercress. Abbreviations: K, kaempferol; I, isorhamnetin; Q, quercetin; Glc; 
611 glucoside, fer, feroloyl; sinp, sinapoyl; p.coum, p-coumaroyl; caf, caffeoyl.

612 aFlavonols co-elute.

613

614 Table 2. Quantification of total and specific carotenoids, in raw and processed

615 watercress samples. Data is presented as absolute carotenoid concentration in

$616 \mathrm{mg} \mathrm{g}^{-1}$ of DW (mean $\pm \mathrm{SD}$ ). Experiment was performed with three biological

617 relicates per group. Significance: ", $\mathrm{P}<0.05 ;{ }^{* *}, \mathrm{P}<0.01 ;{ }^{* \star} \mathrm{P}<0.001$ as

618 compared to carotenoid content of raw watercress. ${ }^{\text {a }}$ Total amount of carotenoids

619 measured spectrophotometrically.

620 Table 3 Concentration of individual and average total glucosinolates in raw and

621 processed watercress samples. Data is presented in $\mathrm{mg} \mathrm{g}^{-1}$ of DW (mean $\pm \mathrm{SD}$ ).

622 Experiment was performed with three biological replicates per group. Significance:

$623{ }^{*}, \mathrm{P}<0.05 ;{ }^{* *}, \mathrm{P}<0.01 ;{ }^{* \star}, \mathrm{P}<0.001$ as compared to carotenoid content of raw

624 watercress.

625

626 